\title{
Unfolding the Space Between Stars: Anthropology of the Interstellar
}

\author{
Michael P. Oman-Reagan \\ Department of Anthropology \\ Memorial University of Newfoundland
}

\begin{abstract}
:
In this anthropological account of the "interstellar" - the vast expanses of outer space between the stars - I take interstellar travel as an object of ethnographic study. First, I examine three interstellar space projects: NASA's Voyager 1 spacecraft; 100 Year Starship's manifesto on their quest to travel to another star; and SETI's search for life in the universe. Finally, I turn to corresponding examples of interstellar travel in speculative fiction.

In 2013, NASA announced a transmission from the Voyager 1 spacecraft as the "sound of interstellar space" and marked it as crossing a boundary into the "space between stars." Organizations like 100 Year Starship and the Interstellar Message Composition program at SETI describe interstellar travel in terms of spacecraft, listening for signals, and active transmission. Fiction and science also co-render humans into interstellar scale via speculative technologies like artificial intelligence, instantaneous travel across the universe by "folding space," and the "generation ship," in which generations of crewmembers live and die during a multi-year voyage to another star.

This ethnography of interstellar ontologies across multiple sites and scales builds on feminist science studies (Haraway), recent work on abstractions as scientific things (Helmreich), and the concept of hyperobjects - non-human entities that are massively distributed in time and space (Morton). As interstellar space moves between abstraction, text, place, and object, I find that it unfolds to reveal a constellation of potentially inhabited worlds inscribed by both scientists and speculative fiction; what was remote, insensate, and desolate becomes intimate, poetic, inhabited.
\end{abstract}

Keywords: Science; Speculative Fiction; Object-Oriented Ontology; Deconstruction; Space

\section{Please cite as:}

Oman-Reagan, Michael P. 2015. "Unfolding the Space Between Stars: Anthropology of the Interstellar." SocArXiv, Open Science Framework. Manuscript, submitted February 4, 2017. osf.io/preprints/socarxiv/r4ghb/

\section{A version of this paper was presented as:}

Oman-Reagan, Michael P. 2015. Unfolding the Space Between Stars: Anthropology of the Interstellar. Paper presented at the Annual Meeting of the American Anthropological Association, Denver, November 21. 


\section{Unfolding the Space Between Stars: Anthropology of the Interstellar}

In this anthropological account of the "interstellar" - the vast expanses of outer space between the stars - I take the world of interstellar travel as my object of study. Interstellar travel describes, on the one hand, an activity that has not yet happened and is not possible today, and on the other hand, a concept that is readily understood as having a world-like coherence.

When astronaut Mae Jemison describes 100 Year Starship - a project to achieve interstellar travel within one hundred years - she cites creation stories, cosmologies, science fiction, and her hopes of discovering a "better version of ourselves" in space (100YSS 2014:n.p.). Dr. Jemison's narrative unfolds interstellar space; what was remote, insensate, and desolate becomes intimate, poetic, inhabited.

Jemison's world of interstellar travel emerges at the intersection of space science and speculation, simultaneously existing outside what anthropologist Wayne Fife (n.d.:7) describes as "standard physics, social formations, economic orders, and/or existing forms of cultural logic" and yet also within the realm of the possible. Interstellar travel thus straddles a line between what Fife (n.d.:7) calls a "world of imagination" and an "imaginary world," flowing back and forth, oscillating between existence as possible place or object and signification of something speculative and potentially unknowable at an almost inconceivable scale. In order to explore this oscillation between place and object, between imagined and imaginary, I look to the activities of organizations working around interstellar travel and communication such as 100 Year Starship, NASA, and SETI as well as depictions of interstellar travel in science fiction film (Star Trek), television (Ascension), and books (Dune).

In 2013, NASA announced that a transmission received from the Voyager 1 spacecraft represented the "sound of interstellar space" (NASA JPL n.d.:n.p.). For some NASA scientists, 
reception of this signal marked the moment that Voyager 1 crossed a boundary into the "space between stars" (NASA JPL n.d.:n.p.). Similarly, organizations like 100 Year Starship and the Interstellar Message Composition program at SETI (Search for Extraterrestrial Intelligence) also describe interstellar travel in terms of the movement of spacecraft. However, SETI challenges this materiality of travel by approaching interstellar space in terms of listening for signals from worlds circling other stars, and through discussions about actively transmitting messages to those potentially habitable worlds. Fiction and science also co-render humans to interstellar scale via speculative concepts like artificial intelligence, instantaneous travel across the universe by folding space, and the concept of a generation ship, a spacecraft in which generations of crewmembers live and die during a thousand-year voyage to another star.

To analyze these worlds of interstellar travel, I draw on Timothy Morton's object-oriented ontology (Morton 2011), hereafter usually abbreviated as OOO, as well as his concept of hyperobjects - non-human entities that are "massively distributed in time and space relative to humans" (Morton 2012:232). I bring Morton's interpretation of an ontology of objects themselves and his idea of hyperobjects in dialogue with some ideas from Jacques Derrida. I use the tensions and relations between the formalist approach in Derridean deconstruction and the deconstructionist materialism of $\mathrm{OOO}$ to examine how interstellar travel might be understood as even more than only an imaginary world or a world of imagination, as well as the multiple ways the interstellar spans ontologies, sites, and scales as text, object, and hyperobject.

In order to do ethnography within these speculative interstellar ontologies I also draw on Haraway's critical feminist science studies (e.g., 1991a; 1991b) and recent work around abstractions as scientific things (Helmreich 2014). I begin in space, thinking through what it means to try and do anthropology of the interstellar while exploring some experimental theoretical 
frameworks. I then draw on those frameworks to look at three examples of "objects" (as objectoriented ontology would call them) as they engage with interstellar space: NASA's Voyager 1 spacecraft; 100 Year Starship's manifesto on their quest to travel to another star; and SETI's search for life in the universe. Finally I turn my analysis to three examples of interstellar travel in speculative fiction.

\section{Interstellar Coyote Things}

The subjects are cyborg, nature is Coyote, and the geography is elsewhere. - Donna J. Haraway [Penley and Ross 1991:4]

How can I approach interstellar space as an object of anthropological study? Choosing any aspect of outer space as a field site results in a kind of dizzying scalar remixing and an accompanying sense of vertigo. The site may seem familiar at first, such as a forest, a mountain, a river, but the scale is strange - for example the satellite's eye view of these Earthly locales from space through which a forest, mountain, and river become textures more than places. Alternatively, the scale is familiar, such as a geologist examining a rock, or a gardener growing lettuce in a greenhouse, but the site is strange - the rock, the geologist, the greenhouse, and the gardener all turn out to be on Mars. Interstellar space fluctuates in similar ways but at more extreme scales, moving between imaginary and imagined world, and between possible object and signification of the speculative and unknowable.

Returning to Haraway's phrase: "The subjects are cyborg, nature is Coyote, and the geography is elsewhere" (Penley and Ross 1991:4). These words have become a motto for my attempts to wrap anthropology around outer space (and other places anthropologists are sometimes cautioned to avoid). It turns out that Haraway's description of nature as Coyote is also an answer 
to a question, as she explains in an interview with Constance Penley and Andrew Ross:

Folks get mad because you can't be pinned down, folks get mad at me for not finally saying what the bottom line is on these things: they say, well do you or don't you believe that nonhuman actors are in some sense social agents? [Penley and Ross 1991:4]

In answer to the question "do you or don't you believe that nonhuman actors are in some sense social agents?” Haraway says, in part, “nature is Coyote” (Penley and Ross 1991:4).

When I think about outer space, the geography seems intuitively elsewhere (that intuition may also be something to ask questions about), and the subjects seem clearly cyborg (again, more questions arise from this ease of acceptance). But what does Haraway mean when she says nature is Coyote? Importantly, she does not say coyote, instead it is the proper name, it is Coyote. Coyote comes onto the scene for me because outer space is a trickster - at once familiar and strange or strange and familiar in equal and unequal parts, remixed and shuffled in order, scale, and site. The place out there that we call interstellar space, says through Coyote: I am here, available, conceivable and I am nowhere, impossible, and beyond. Space, seen as a kind of nature, fits within Haraways's cyborg-like Coyote nature, because it disrupts the dualisms that have persisted in Western traditions (Haraway 1991a), as Haraway explains:

Nature emerges from this exercise as "coyote." This potent trickster can show us that historically specific human relations with "nature" must somehowlinguistically, scientifically, ethically, politically, technologically, and epistemologically — be imagined as genuinely social and actively relational. And yet, the partners in this lively social relation remain inhomogeneous. Curiously, as for people before us in Western discourses, efforts to come to linguistic terms with the nonrepresentability, historical contingency, artifactuality, and yet spontaneity, necessity, fragility, and stunning profusions of "nature" can help us refigure the kinds of persons we might be. We need a concept of agency that opens up possibilities for figuring relationality within social worlds where actors fit oddly, at best, into previous taxa of the human, the natural, or the constructed. [Haraway 1991b:21]

Haraway calls for a relational thinking with nature. Thinking about space as Coyote with Haraway, 
then, prompts me to ask: What kind of active relations do we have with interstellar space?

One possible answer comes from Stefan Helmreich's research on the anthropology of waves (2014). Helmreich argues that when studying scientific things, like waves, the materiality of those things cannot be separated from the formalisms describing them (2014:267). Like Helmreich's anthropology of waves (2014) and Natasha Myers' similar but more embodied anthropology of molecules (2008), could it be that our relationality with interstellar space is only apprehensible through abstraction (Helmreich 2014)? Haraway's nature-Coyote prompts me to wonder if we can have active relations with interstellar space - in both its materialist and formalist guises, with the abstraction and the thing itself. Insterstellar space is a scientific thing that is both somewhat empirical and conceptual, and as Helmreich points out such epistemic hybridity makes people nervous (Helmreich 2014:271). Perhaps Haraway's Coyote could be thought of as the spirit animal representing Helmreich's epistemic hybridity as emblem, or even as totem.

Philosopher Timothy Morton is clearly quite nervous about these Coyote-natures. Their epistemic hybridity seems fascinating, intriguing, and thought-provoking when considering sound waves or ocean wave science, but what about the trickster natures in nuclear weapons and waste, climate change, toxic spills, mass extinctions, or waves as tsunamis, and other such threats? In response to the era of anthropogenic influence on the planet which has been dubbed the Anthropocene epoch, Morton tries to "get a grip" on our new "ecological reality" (Morton 2012:229). Morton argues that the Anthropocene is only really potent, however, because it magnifies something already fundamental in reality, the nonexistence of the present, and makes that fact visible to humans (2012:229). The non-human thus occupies the human because as Morton writes, riffing on Derrida, "there is not outside-human text" (2012:231). Morton says the "gigantic beings" of the Anthropocene (objects such as radioactive materials, global warming, etc.) 
have always already inscribed the end of the present, inscribed doom - and he calls these objects that are massively distributed in time and space relative to humans "hyperobjects" (2012:231).

Despite being born into this nervous doom about Coyote-natures, through a kind of apocalyptico-genesis, Morton's concept of the hyperobject is useful for thinking about enormous non-human entities of all kinds. Hyperobjects, Morton says, are "so massively distributed in time and space that they end the idea that time is a neutral container that is outside the physical universe" and at this scale, "there is no me, no human even, worth talking about" (2012:233). This is a fitting description of experience in the face of interstellar space. In Morton's hyperobject, I see something like an ur-Coyote. The hyperobject is a concept for a thing that defies everything we think we know about a thing, the ultimate, original trickster.

Prior to encountering Morton's thinking, I wouldn't have thought of something at this scale as an object at all. I might have called it a place, or a space, or perhaps just: what is, as in the space between stars simply is or is said to be. In Morton's discussion of geologic time as yet another scale at which the human perspective becomes less and less useful, he calls such spans of time "uncanny" - a perfect word for thinking at this scale. This particular kind of temporality is just one characteristic of hyperobjects. Morton says they have other properties in common:

They are viscous, which means that they "stick" to beings that are involved with them. They are nonlocal; in other words, any "local manifestation" of a hyperobject is not directly the hyperobject. They involve profoundly different temporalities than the human-scale ones we are used to. In particular, some very large hyperobjects, such as planets, have genuinely Gaussian temporality: they generate spacetime vortices, due to general relativity. Hyperobjects occupy a high-dimensional phase space that results in their being invisible to humans for stretches of time. And they exhibit their effects interobjectively; that is, they can be detected in a space that consists of interrelationships between aesthetic properties of objects. [Morton 2013:1]

Interstellar space might not exactly be a hyperobject, as Morton describes them, although I think it is - even if that means we need to reconsider Morton's hyperobject, something I am doing here 
anyway by thinking alongside his ideas. However it is not my intention to hold up various events and ideas against Morton's list, as if it were a ruler, and ask how they measure up. Instead, these characteristics will emerge or not in more subtle ways and under different names as I look at interstellar space through the lens of his and other ideas.

Morton calls these vast entities objects rather than spaces, processes, or phenomena because he is working within the framework of object-oriented ontology (OOO), an attempt to "rethink realism in the wake of the distinctly anti-realist philosophies" (Morton 2011:164). OOO rejects both nature and matter while asserting that real things exist and differentiating those things from a more general and amorphous kind of matter (Morton 2011:164-165). Within OOO, Morton writes, "objects encounter each other as operationally closed systems that can only (mis)translate one another" (2011:165) and as such in OOO there are only objects, no subjects. OOO's concern with objects at every scale, their dark nature, unknown sides, and strangeness makes it an interesting way to think about something as vast, and seemingly unknowable as interstellar space.

I bring Morton's ideas to this anthropology of the interstellar because he formulated the hyperobject as a response to the challenges of vast temporal and spatial scales. Thinking about the problem of something like plutonium with a half-life of 25,000 years, Morton concluded that we need to formulate "new ways of thinking about objects and revise our ideas about the subjects that think about them" (2011:167). Similar problems arise when considering interstellar space.

Ontological approaches might be useful in these places where other anthropological concepts seem to come up against limits. How do we study the "culture" of interstellar space, for example? Martin Holbraad suggests that the concepts we have at our disposal might be "inadequate to describe our data properly, let alone to 'explain' or 'interpret' it" (Carrithers et al. 2010:180). Holbraad argues that the anthropological task, then, is not to account for why "ethnographic data 
are as they are," but instead to understand what they are - rather than explanation and interpretation, Holbraad calls for conceptualization (Carrithers et al. 2010:184). A similar argument is made in Henare et al. 2006, namely that the purpose of anthropology is the "generation of concepts" and that an ontological approach "more than any other" takes things "encountered in the field 'seriously"' (Carrithers et al. 2010:154). Because an ontological approach creates space for looking at multiple realities and multiple ontologies it can "generate new concepts that go beyond those that come from 'our' ontology" (Carrithers et al. 2010:154).

Object-oriented ontology is not, however, ontologies but rather an (one) ontology. By using Morton's OOO and his idea of hyperobjects here, I mean to use it as an analytical concept, as a tool to pry loose a simultaneously rusted shut and very slippery concept: interstellar space. I use Morton's OOO/hyperobject framework alongside other tools. I agree with Holbraad when he argues that "to equate culture with ontology as anthropological tools, is to remind us of the value of culture, not to belittle ontology" (Carrithers et al. 2010:174).

I bring Derrida onto the scene here, through a kind of ad hoc séance, both because his concepts challenge me to think in new ways and, as with Morton's thinking, and I want to learn more about these ideas and see if they are useful, helpful, or interesting. Morton entered OOO through deconstruction (Morton 2011) although he describes his thinking as post-Derridean, by which he means it is “within Derrida's continuation of the Heideggerian project of deconstructing the metaphysics of presence" - this is also why he says he "backed into" OOO from deconstruction (2012:235). For Morton, the most significant idea to take from Derrida is that of no reality outside of the text, no object outside of interpretation: [I]l n'ya pas de hors-texte, which has been translated by Gayatri Spivak as both 'There is nothing outside of the text' and alternately as "there is no outside-text" (Derrida 1997:158). Morton finds this double meaning useful but chooses to builds 
on the later translation, "there is no outside-text," and takes it as a way of opening "the problem of what constitutes existence as environmentality" (2012:230).

Morton grabs onto the "nothing" in Derrida's claim that there is nothing outside of the text, and takes that nothingness as the suggestion of a presence, as a thing, a no-thing that $i s$. This echo or object of nothingness, for Morton, then becomes an entry for the non-human, for the shadow of the hyperobject. What could be more Coyote-like than taking Derrida's statement that there is nothing outside the text to mean that nothingness itself can be a thing outside the text. Morton does this, and uses Derrida's deconstruction as a gateway to what he calls a "weird realism" (Morton 2012:230).

The "rift between past and future, appearance and essence" is part of this "nothing" that is outside the text and "a happening that the text must include - exclude in order to be itself" (Morton 2012:235). Derrida's deconstruction emerges from something quite like this rift, a place or concept in a text that Derrida calls an aporia, an impasse or road block. For Derrida, thinking begins in the moment of encountering an aporia, which he describes in several ways, for example:

As "the impossible, the impossibility, as what cannot pass [passer] or come to pass [se passer]: it is not even the non-pas, the not-step, but rather the deprivation of the pas (the privative form would be a kind of a-pas)." [Derrida 1993:23]

"It is not necessarily a failure or a simple paralysis, the sterile negativity of the impasse. It is neither stopping at it nor overcoming it." [Derrida 1993:32]

According to Derrida, it is only at this roadblock where methods do not work that thinking can begin. However, the dilemma encountered in the text is not a conclusion or a hurdle but a problem that requires an even closer reading of the text to understand the contradiction. Such a close reading spotlights the problems in the text, revealing a deconstruction, a process that breaks down and builds anew, a process which ultimately the text does to itself (Derrida 1988, 1997). 
Morton's deconstruction of Derridean thinking based on the aporia of this rift between past and future leads him to OOO, and to understand the universe as made up of discrete, concrete, objects (2012:235). For Morton these objects are real things, however they are profoundly withdrawn, and neither we nor anything else can ever entirely see them (2011:165). In this way of thinking, we have reached the end of the world because there is no world and no worlding, and there never was (Morton 2013:107-108). For Morton there are only objects, relating. So, just when I think I see the ur-Coyote, it recedes into shadow again and it turns out I have only seen the edge of a hyper-Coyote-thing, and being unknowable in a non-world universe becomes its greatest trick.

\section{Voyager 1: Entering}

Voyager is in interstellar space - the space between the stars.

- Dr. Ed Stone, Voyager Project Scientist [NASA JPL n.d.:n.p.]

In 1977 NASA launched the Voyager 1 spacecraft to explore Jupiter and Saturn. In 1990 Carl Sagan proposed NASA turn Voyager around in order to take a photograph of Earth from four billion miles away. This "Pale Blue Dot" image, depicting the Earth as a speck floating in a beam of sunlight, inspired Carl Sagan's eponymous book and corresponding new sense of scale in his and other popular space writing (Sagan 1994). In 2012, Voyager recorded the sound of "waves of particles wiggling interstellar plasma" and transmitted that sound back to Earth. For NASA scientists, this "sound of interstellar space" marked the moment voyager began an "interstellar mission" in the "space between stars" (NASA JPL n.d.:n.p.). Alongside this text, NASA provides a video of an animated chart with both the data and the "sound of interstellar space" - this data visualization and the accompanying sound functions as a record, a demonstration of Voyager entering interstellar space. 
This is, however, only one way that NASA tells the story of Voyager's entry into interstellar space. There is another in a press release titled "NASA Spacecraft Embarks on Historic Journey Into Interstellar Space" (Cook et al. 2013:n.p.). In the press release, the boundary marking interstellar space from the non-interstellar is less clear. The press release explains that "Voyager 1 first detected the increased pressure of interstellar space" on the bubble of charged particles around the sun, known as the heliosphere, in 2004 (Cook et al. 2013:n.p.). This finding prompted scientists to begin looking at Voyager's data more closely for evidence of "interstellar arrival” (Cook et al. 2013:n.p.). The press release also reveals that it was not until a coronal mass ejection from Earth's Sun in March 2012 reached Voyager's location 13 months later that scientists were able to identify, from the vibrations in plasma around the spacecraft, the density of plasma they "expect to find in interstellar space" (Cook et al. 2013:n.p.). This data showed a "durable change" in the density of plasma on August 25, 2012 and the press release reports that the "Voyager team generally accepts this date as the date of interstellar arrival" (Cook et al. 2013:n.p.). And so Voyager is in interstellar space and was before we knew it, in part, because to talk about interstellar space this way Voyager must either be in or not-in interstellar space. This problem arises because, for NASA, interstellar space is a place.

As a place, interstellar space does not withdraw as it might when considered through objectoriented ontology (OOO), rather interstellar space can be seen and known as a horizon and so our spacecraft can enter it - crossing a boundary between here and there. NASA's public language suggests certainty about this boundary, and the world of interstellar travel they construct defines the crossing by placing it temporally and spatially:

Voyager 1 has entered interstellar space. The NASA spacecraft, which rose from Earth on a September morning 36 years ago, has traveled farther than anyone, or anything, in history. Now Voyager 1 is in the space between the stars. How did 
Voyager 1 get there? How do we know and where is it going? [NASA JPL n.d.:n.p.]

Now, NASA says, at over 11 billion miles from Earth's Sun, Voyager's next crossing may be the outer limits of the "Sun's sphere of influence" as it enters the "interstellar medium" past a boundary zone where solar and interstellar winds meet (NASA JPL n.d.:n.p.).

Has NASA been to interstellar space because this spacecraft has? Have we, as a human species, been to interstellar space? Is interstellar space more known, more familiar because Voyager has detected and transmitted back data about plasma vibrating, oscillating at the right pitch so as to sound like interstellar space? Does listening to this audio mean that I too have been in interstellar space? Writing about geological time, Morton describes it as an "abyss whose reality becomes increasingly uncanny, not less, the more scientific instruments are able to probe it" and argues that in cases like this "knowledge ceases to be demystification, if it ever was" (Morton 2012:233).

Similarly, as Voyager probes the inconceivable spaces between the influence of our sun and the interstellar medium, we seem to know even less about what interstellar space is at the same time that we tell triumphant stories about entering it. And yet, as the next section will discuss, we are still itching to go there. Crossing the horizon of interstellar space, we find yet another horizon, and having entered interstellar space we still talk about how we will get there. Perhaps this is because, as OOO suggests, there is no horizon. A hyperobject like interstellar space is so vast it destroys the horizon and "the world — as a significant, bounded, horizoning entity_disappears" (Morton 2013:104). As Voyager enters interstellar space, it erases the interstellar as a world. 


\section{100 Year Starship: Manifesting}

This logo is made from stars.

It's a dynamic star map that shows the closest star to you directly overhead when you look up. And since the Earth is constantly moving, our logo features different stars based on where you are and what time it is.

- Explanation of the 100 Year Starship logo [100YSS n.d.:n.p.]

Arriving at the 100 Year Starship (100YSS) web site, I see an aerial photo of a launch pad at the John F. Kennedy Space Center on Merrit Island, Florida. Text overlayed on the image tells me this is "Launch Pad 39A." When I try to scroll down to see more of the site, instead of the page moving vertically, the image zooms out!

As I continue to scroll, I find I am moving further and further away from the launch pad on the Florida island. The sea comes into view, then roads, the island, the outline of the Florida coast. I can see most of the southeastern United States, part of Mexico, The Bahamas, Cuba, and suddenly I've scrolled out far enough that I see the entire Earth, a blue globe floating against a black starry background. The "Google Earth" logo appears in the upper right hand corner of the window, revealing that I am in a virtual cartographic territory - a map of satellite images and artistry made by a big-data-feeding corporation. I continue zooming out to find that I can go further than I expected, as the Earth becomes smaller I reach the moon and the zooming stops. Text appears on the screen announcing: " The far side of the Moon is the farthest a human has ever traveled. That was almost five decades ago. Isn't it time we move forward?" (100YSS n.d:n.p.).

This map has done its job. I feel like arriving at the far side of the moon was hardly any effort at all. All I had to do was scroll for a bit to zoom out on a digital map, and suddenly there I was, as far from Earth as humankind has ever travelled. But now, on top of this image of the Moon and Earth the web site offers up an artistic portrait, an image of two figures silhouetted by a campfire. I can see the curvature of the horizon, the planetary locale they are sitting on - but the 
scale is wrong, exaggerated, and the curve of the globe is visible. It reminds me of Antoine de Saint-Exupéry's illustrations of The Little Prince (1943) in which the young prince stands on a small planet or asteroid, like a toy soldier standing on an apple. The two figures seated in front of the campfire are looking up at a night sky dense with stars; one is pointing up at something. An icon appears over them, a circle around a triangle. It is the near-universal symbol for play, indicating that this is a video. I click play and the video begins:

[animation of two figures sitting beside a campfire looking up at the stars - scene continues and a voiceover begins]

From the first moments of human history We have gazed in awe at the infinite sweep of the heavens

[animation of lines connecting stars to form constellations in a starry sky]

The stars formed our creation myths and cultures

[animation of two human figures sitting beside a campfire warming their hands]

The stars have witnessed every human achievement And each foible that has set us back

[animation of a sailing ship at sea two human figures watch the stars from the deck a shooting star soars across the sky]

And they're still up there

Waiting for us to advance enough to reach them

[animation of a sailing ship at sea sailing toward the horizon at night under a dark starry sky]

Once we relied on the stars to navigate the Earth

Now we're leaving the Earth to navigate the stars

[animation fades to reveal the voice is that of Dr. Mae Jemison, the first

black female astronaut, she is standing against an empty black

background, and continues speaking]

Humanity and our planet stand at an inflection point 
[text appears on screen: “Dr. Mae Jemison, Leader 100 Year Starship”]

Will we continue on our current path of short-term thinking?

A path that appears safe but flirts with stagnation

Or do we come together and push for humanity's next giant leap forward?

At 100 Year Starship, we are calling on members of our generations [sic] to complete a clear mission:

Make the capabilities for human travel to another star a reality within the next 100 years.

Because just as past exploration pushed breakthroughs in agriculture, communications, energy, transportation, materials, and medicine, the greatest rewards of interstellar travel will be felt here at home.

We believe that pursuing an extraordinary tomorrow will create a better world today.

And who participates makes all the difference.

[video fades from Jemison back to animation depicting many hands clasped together, Jemison voiceover continues]

Join us on this audacious journey

[clasped hands release to reveal the Sun high in the sky]

The road to another sun won't be easy

[animation of sun in the sky is revealed to be a ship flying up through the clouds]

But if it were we wouldn't grow

No matter how hard things have gotten

[animated ship leaves the clouds, continues flying against a starry background]

No matter how dark

Humans have never failed to look up

[animation of two human figures sitting beside a campfire looking up at the stars] 


\section{Up for inspiration}

[animation of a sailing ship at sea, two human figures watch the stars from the deck, a shooting star soars across the sky]

\section{Up for endless possibilities}

[animation showing Earth from space]

\section{With a humble craft hurdling toward a distant star}

[animation of a figure looking through a telescope at a starry night sky, the shooting star crosses the sky again]

\section{Built by the best hearts, minds, and hands} We'll discover a better version of ourselves

[animation reveals the shooting star is a craft, flying past the planets of our solar system]

\section{And bring a brighter, more harmonious, more sustainable life}

[animation of craft as it flies to a distant star, the star becomes part of the 100 Year Starship Logo, under the logo the words "LOOK UP" appear]

To the future generations who will call our beautiful blue planet their home.

[music and image of logo against a field of stars]

[music fades out as image fades to black]

The video, words, and production are inspiring. My impulse, my desire even, is to argue that this 100YSS video reflects a world of interstellar travel, but Morton argues such worlds don't exist, there are no ontological other worlds, only other things. Yet here it is as far as I can tell, a world of imagination inspiring me to think about and experience the potential of interstellar travel. Mae Jemison tells a story about the possibilities of interstellar travel, of historical human relations with the stars, and challenges us as a species to continue dreaming about places unknown. If this is not a world, what is it? Looking for other ways to read this video, I will consider this instance of 
interstellar travel as a text, and therefore a citation. As OOO turns away the possibility of a world, it may be useful here to think about writing.

Derrida argues that every sign must be repeatable to be meaningful, it must be able to be used in a new context. This iterability necessarily also requires a shift in context - iterability is a repetition with difference (Derrida 1988:7). In this text, Jemison is repeating tropes about exploration, about colonization, expansion, human destiny, and others. Jemison is also citing Herman Melville when he wrote "I am tormented with an everlasting itch for things remote. I love to sail forbidden seas" (1892:12), and she is then also citing Carl Sagan over 100 years later when he cited Melville in Pale Blue Dot (1994). This repetition with difference is, then, a kind of Derridean iterability. Melville's "itch for things remote" was not written for the context of Voyager turning back toward Earth for one last photograph of home, or for Jemison's September 1992 trip into space on the Space Shuttle Endeavour, or her childhood watching Nichelle Nichols play Lieutenant Uhura on Star Trek and dreaming of visiting space one day - but Melville's idea is still cited here and becomes repetition aligned with alterity.

When Jemison says the stars are "still up there, waiting for us to advance enough to reach them" she is also citing Sagan when he wrote: "Maybe it's a little early. Maybe the time is not quite yet. But those other worlds - promising untold opportunities - beckon. [ . . ] Silently, they orbit the Sun, waiting" (1994:xviii). Jemison speaks in Sagan's language, inspired by Voyager's distant view of the Earth - across four billion miles of space. Sagan wrote that Melville spoke "for all wanderers in all epochs and meridians" (1994:xv) and again now, Jemison speaks for all of us wanderers who itch for things remote.

Derrida points out that writing is a form of communication at a distance; the one who writes and the intended addressee are separated spatially and temporally (e.g. 1988, 1993). This means 
we can never be sure our writing will reach the intended addressee, we can never be sure what we mean to say will be interpreted correctly, and the addressee can never be sure of the author. Since Plato, philosophy has considered writing dangerous and secondary for these reasons. However, Derrida concludes that these issues also apply to oral, gestural, or other forms of linguistic communication, and so he uses the term writing to refer to all linguistic functions (1988:8-21). As a consequence of this, Derrida finds that speech is in fact a form of writing, and writing becomes a term to refer to the operation of language in general. For Derrida then, writing also comes before experience and this contributes to his deconstruction of the metaphysics of presence (e.g., 1988, 1993).

Morton finds that "the apparent traces of hyperobjects appear as indexical signs" and that what we take as the "present moment" is actually a shifting and ambiguous stage - the appearance of things, he argues, is "the past of a hyperobject" (Morton 2013:90). Both Derrida's understanding of writing as prior to experience and Morton's deconstruction of the present moment thereby argue against the metaphysics of presence. Without a now, or an eternal, we are left with a picture of interstellar space without nature, without matter, and without a present (Morton 2013:92). Instead, we find interstellar space to be a series of indexical signs - traces left in the writing of Melville, Sagan, and in the 100YSS manifesto through Jemison's inspirational vision of possible human futures in space. In these ways, the text of interstellar space is beamed backward into the past and appears to us as a 'present' through writing. 


\section{SETI: Signing}

The universe beckons, and we can do better than to declare that future generations should endlessly tremble at the sight of the stars.

- Seth Shostak, SETI [2015:n.p.]

When Seth Shostak, Senior Astronomer and Director of Research at the SETI Institute, says "the universe beckons" - who or what is he referring to? Who or what is doing this beckoning?

In an episode of the online radio program Star Talk titled "The Future of Humantiy," host and astronomer Neil deGrasse Tyson spoke with Elon Musk, CEO of Tesla and SpaceX, about the possibility of a "superintelligent AI" (artificial intelligence) and the threat it could pose to humans (deGrasse Tyson 2015a). “Aliens," deGrasse Tyson later wrote, "will make pets of us" (deGrasse Tyson 2015b). Media reporting and reactions in social media ranged from calling the conversation an instance of light-hearted joking to taking their concern as a serious assessment of the threats waiting for us in interstellar space.

This conversation came during a moment when the SETI Institute, dedicated to the Search for Extraterrestrial Intelligence, announced their interest in returning to "active SETI" - the practice of transmitting messages in the hopes of contacting intelligent life elsewhere in the universe. On February 13, 2015 scientists from SETI met at the annual meeting of the American Association for the Advancement of Science (AAAS), to discuss a return to active SETI.

The day after that meeting, on February 14, the SETI Institute held a private, invitation only workshop at their headquarters in Mountain View, California. Douglas Vakoch, SETI's Director of Interstellar Message Composition, shared the agenda with me in email correspondence (February 12, 2015). The session included presentations from nine scientists and other analysts and researchers on topics including: arguments against active SETI; risks of contact; signs of life in planetary environments; how to use planetary radar systems for transmitting messages; the 
politico-legal situation for transmissions directed at extraterrestrial life; a panel on ethics titled "Loneliness in the Cosmos;" and a keynote presentation on "Messaging Morality" from Holmes Rolston III, a philosopher of environmental ethics, religion, and science. The topics of the day, and the keynote speaker's focus, were primarily on morality, which reflects Vakoch's openness to interdisciplinary and non-traditional thinking about messaging. Vakoch is not only director of message composition at SETI, but also a professor of psychology at the California Institute of Integral Studies, an institution known for its fusion of traditional academic approaches with a Jungian-Buddhist approach similar to that of Naropa University in Boulder, Colorado.

The meetings at the AAAS and SETI Institute generated press and debate across publics and within the SETI scientific community as well. A statement on the possible dangers of Active SETI was released and signed by Elon Musk and 27 others including Denise Herzing whose SETI work includes ethnographic and linguistic studies in the Wild Dolphin Project, science historian George Dyson, and others. The statement uses the acronym METI, a synonym for active SETI that stands for Messaging to Extraterrestrial Intelligence. The statement warns of the "unknown and potentially enormous implications and consequences" of METI, concluding:

Intentionally signaling other civilizations in the Milky Way Galaxy raises concerns from all the people of Earth, about both the message and the consequences of contact. A worldwide scientific, political and humanitarian discussion must occur before any message is sent. [Azua-Bustos 2015:n.p.]

While the call for worldwide participation and discussion is appropriate, the statement was widely regarded as being an anti-METI document. It also provoked Seth Shostak's March 27 New York Times Op-Ed arguing in favour of active SETI which is quoted in the opening of this section (Shostak 2015:n.p.). 
On the one hand, the signatories of the METI Statement are expressing fear of disaster. In this case it is an especially fitting reference to the etymology of the word disaster, as Morton explains:

Literally, a disaster is a fallen, dysfunctional, or dangerous, or evil, star (dis-astron). But such disasters take place against a stable background [ . . . ] To be a disaster, a "star" such as a meteor must deviate from this harmonious arrangement or celestial machinery. [Morton 2013:15-16]

The possibility of intelligent life elsewhere then becomes a dis-aster, a bad star, and a deviation from "harmonious arrangement" in several ways, one of which is the destruction of a previously familiar and anthropocentric universe. This is, in a sense, a penetration of interstellar space into Earthy space. SETI's call for active messaging, then, summons interstellar space as a hyperobject in one of its most threatening guises.

Within the text of the statement, however, there are other less cosmic but no less real concerns. The statement warns that opponents of METI would "vocally condemn METI transmissions" which would confuse the "public about, and [imperil] funding for, bona fide scientific endeavours related to extraterrestrial life" (Azua-Bustos 2015:n.p.). The very Earthy concern of possible threats to scientific funding (for research on the existence of extraterrestrial life) is seen as standing in the way of the advancement of the search for that extraterrestrial life.

Taken another way, signing the METI Statement also creates a trace of the signatories belief in the existence of life elsewhere - a statement proclaiming that we are not alone in the universe. Signing the METI Statement signals that the signatories believe there is not only life beyond Earth, but that there is intelligent life. Threat also becomes the sign and signal of intelligence elsewhere and otherwise.

In this conundrum of SETI and METI the tables are turned on humankind. It is no longer a question of what we might come to know of interstellar space worlds, but of what interstellar space 
will come to know about us. Shostak's solution to this question is to broadcast a signal into space. Although psychologist Douglas Vakoch is the Director of Interstellar Message Composition at SETI, it is often Shostak who spoke publicly around this time about what we should send in an active SETI transmission. Repeatedly, though interviews, articles, tweets, and editorials, Shostak proposed that METI's next message should be a text: the entirety of the Internet. Thinking with Derrida's interest in citations and signature, I wonder: Might sending the whole Internet into space be an ultimate act of human citation? Our cosmic signature?

I find several instances of "signature" here. First, the scientific practices of SETI, which are to search within signals among the background noises of the cosmos to find a signature of life elsewhere. Second, the statement of intent to actively send a composed message from Earth which implies a sender and a signatory whose signature reads something like a cosmic gift tag: "To: Aliens, From: Earth." Alongside this active transmission intent sits the third instance, the signature of the METI Statement from those who express concern about the consequences of active, intentional communication and the doom it portends (to research funding or to the planet).

In order to function and be readable, Derrida says a signature must have "repeatable, iterable, imitable form" and must be able to be "detached from the present and Singular intention of its production" (1988:20). The signatures from Earth to the interstellar intelligence and the signatures we listen for in return, must therefore be iterable to be signatures. Derrida notes that a "signature implies the actual or empirical nonpresence of the signer" (1988:20). Considered in terms of signatures, SETI's activity at the level of messaging and communication could be read as inscribing signatures both on behalf of the humans of Earth (with or without the presence of us all), and on behalf of the non-presence of an unknown author of possible interstellar signals coming from space and received here. 
In this deconstruction of SETI messaging, the organization's communication program then becomes responsible for a cosmic signal gift-exchange and inscribes incoming signals with an alternate tag that reads "To: Earth, From: Aliens." From the perspective of OOO, SETI thus works in messages as objects, which are signed either from or to space - and in so doing, SETI signs the interstellar with marks that move it from an empty frontier into a constellation of potentially inhabited worlds inscribed by both scientists and speculation.

\section{Science Fiction: Speculating}

Deep in the human unconscious is a pervasive need for a logical universe that makes sense. But the real universe is always one step beyond logic.

- Frank Herbert [1965:363]

\section{Part 1. Returning V'ger}

In Star Trek: The Motion Picture, the crew of the starship Enterprise is sent to investigate an enormous entity that is travelling through interstellar space toward Earth (Wise 1979). After passing through the outer layer of cosmic-scale energy clouds surrounding it, and entering the inconceivably huge ship (within their own enormous space vessel) the crew finds that this alien ship contains enormous chambers holding worlds and entire star systems (or at least representations of them). At the center, they discover the mind behind this vast living intelligence, a machine entity named V'ger - described by one Star Trek fan wiki as "one of the most extraordinary lifeforms ever encountered" (Memory Alpha n.d.:n.p.).

In the theatrical release (Wise 1979) V'ger is said to be 82 astronomical units (AU) in diameter, a measurement that was changed to two AU in the 2001 Director's Edition - this smaller number is still equal to the diameter of Earth's orbit around the Sun. The original size of 82 AUs meant the ship was reported to be twice as large as the distance between Earth and Pluto. However, 
it is not the massive size of the ship (at either measurement), its power, or technology that make it so extraordinary but rather its origin. At the center of this massive, evolving ship in its oldest part, V'ger is revealed to be built around the Voyager 6 spacecraft, an imagined continuation of the Voyager program that launched Voyager 1 and 2. Having been programmed to "learn all that is learnable and return that knowledge to the creator," the Voyager 6 spacecraft expanded and evolved into a sentient being who then returned to Earth in search of its creator (Wise 1979). V'ger collected information during a voyage across interstellar space and then wanted to return that knowledge, wanted to follow its programming qua creation story.

The first draft of the script, from Star Trek creator Gene Roddenberry, was originally titled "The God Thing" (Porter and MacLaren 1999:45). This vast entity, this God Thing of the early script, persisted in the story and became V'ger, a vast non-human entity that threatened Earth and all human life while initially refusing to accept the idea that humans could be "the creator" it sought. The idea of an entity like V'ger could be read as a sentient hyperobject, something like what Morton refers to as "the last god":

The very pinnacle of modernity, encapsulated in Robert Oppenheimer's 'I am become death, shatterer of worlds', is the arrival of what Heidegger would have called the last god if he had been able to include nonhumans in his view. Heidegger simply was unable to ascertain how this last god would manifest in the very core of technological enframing. The poison is indeed the saving power, or not. For it is gigantic nonhuman beings $[\ldots]$ who bring about the end of the world. [Morton 2012:232]

V'ger is not a destroyer of worlds, but a collector, and a child of both Earth and interstellar space who upon returning home represents the greatest threat to humanity imaginable. Moving into and across interstellar space did not transform Voyager 6 into V'ger, rather it was encountering interstellar space in intimate relationality that did this. Where interstellar space could be said to 
withdraw, like all objects do through the lens of OOO, V'ger fought against that withdrawal and collected the universe - gathering suns and planets to bring back to its creator.

Morton proposes that the end of teleology is the end of the world, which is not an "instant vaporization," but rather "a lingering coexistence with strange strangers" (2013:95). In the conclusion of Star Trek: The Motion Picture, V'ger decides that it must merge with a human consciousness in order to overcome the limits of its logic-driven machine thinking. From the standpoint of OOO, this is not a merging of worlds (human and non-human), but rather of two objects being one together. A crewmember and V'ger become one, and this new thing embodies both destroyer of time, space, and worlds as well as a new relationality with interstellar space as the lingering coexistence with strange strangers.

\section{Part 2. Generating Ships Without Worlds}

In the Canadian/American television miniseries Ascension (Williams 2014), a crew of 600 people is sent into space on a century-long voyage to colonize a planet orbiting the nearest star. They travel aboard the USS Ascension, a generation ship, and their destination is Proxima Centauri - a star 4.24 light-years from Earth's Sun. Generation ships, also known as "World Ships," are a form of gigaproject - construction on such a massive scale that they could only be accomplished through global cooperation (Ceyssens et al. 2012). Drawing such massive resources together for the construction of an "ecologically self-contained 'world-ship"" is something a civilization might be forced to do when faced with a planetary disaster, such as their star entering the red giant phase, in order to transfer their civilization to another planet (Matloff and Pazmino 1997). 
Ascension, a made-for-television story of the life of the crew aboard such a generation ship, was inspired by Project Orion - a real proposal from the 1950s to build an interstellar ship powered by nuclear pulse propulsion. Orion was imagined during the cold war, amidst fears that the standoff would turn into an active global nuclear war and humans might need to abandon Earth. Ironically, the Orion spacecraft would have been propelled through space by a series of atomic bombs detonated behind the craft (Ferguson 2002). As conceived, Orion would have been a generation ship traveling within the hyperobject of interstellar space, powered by another hyperobject, atomic blasts. Nuclear weapons politics at the time simultaneously prompted the imagining of an escape route for human civilization and made the project unlikely to succeed despite there being no technical barriers. Scientists re-visiting the Orion Project have suggested new technology could make nuclear pulse propulsion "less unreasonable to consider" (Schmidt et al. 2002:497). "Less unreasonable" could serve as a motto for Morton's era of hyperobjects.

Atomic power, radiation, and the nuclear are recurrent themes in Morton's conception of the hyperobject. They figure alongside the hyperobject of the Anthropocene. They all appear in the moment Morton calls the end of the world, which, he says, has already arrived. In fact, hyperobjects turn out to be responsible for the end of the world (Morton 2013:2-7). So what, then, is a generation ship powered by the very doom it hopes to escape? What, then, is a 'world-ship' without a world? Morton's conception of the end of the world relies on a change in our understanding of foreground and background. He explains that hyperobjects result in us suddenly noticing the background and as a result that background leaves our peripheral vision, it is thus no longer a background but a foreground and everything is foregrounded, everything is seen as an object (e.g., Morton 2011, 2012, 2013). This drive-by simplification does not do justice to 
Morton's argument but does serve the purpose here of setting up a way to talk about a generation ship without worlds.

Like Morton's example of climate change, which brings weather to the foreground and thus ends the illusion of some world in our peripheral vision in front of which life happens, a generation ship is strange and spooky because it claims to take the world, the background, and pack it up. A generation ship imagines an apocalyptic future in which human civilization must escape planetary danger. Yet we have already lived that apocalyptic future on two fronts. First we have been living in the Anthropocene, although we may not have been aware of this. Second, we lived in the Cold War under threat of annihilation and it was during that threat that we designed Project Orion as a possible escape. Do we bring those along with us as well when we leave the Earth?

Morton writes that "worlds need horizons and horizons need backgrounds, which need foregrounds" - without a background, he argues, there is actually no foreground either $(2013: 104)$. This "world" that the concept of a generation ship is supposed to move into the world-ship and carry off to another planet? According to OOO, it doesn't even exist.

In the series Ascension, Episode 2 reveals that the 600 people on board the generation ship have never left Earth, but have been trapped inside a ship grounded here on Earth for 51 years, unwilling test subjects in a closely watched experiment (Williams 2014). The generation ship never left, their world and the horizon they believe they crossed, are illusions. Perhaps then, the generation ship is already here on Earth, or is the Earth itself, and we have always already been living on it.

\section{Part 3. Folding and Unfolding Space}

In Frank Herbert's Dune series $(1965,1969,1976,1981,1984,1985)$, interstellar travel is accomplished through application of the "Holtzman Effect" - an imagined scientific technique for 
folding space at the quantum level. Folding space makes it possible for enormous ships to instantly move from any part of the universe to any other. Because computers (and any thinking machine that could replace a human) are prohibited in Herbert's universe, humans mutated through exposure to the drug Melange (called "the spice") perform the necessary calculations. The spice gives these "Navigators" prescience, and with it the ability to navigate through "foldspace" safely.

Along with prescience, the effects of spice include longer life, greater awareness, and increased intelligence. Thus, interstellar travel in the imaginary world of Dune is accomplished through thought and being, and through a conception of interstellar space as not place, but object. To fold space, two different points in the universe must become one. This collapsing of the spatial brings the object-ness of interstellar space to the surface. To consider interstellar space in the Dune universe through the lens of OOO, imagine interstellar space as a piece of paper. Draw two dots on the paper and then fold it so that the two dots are touching. Through this paper metaphor, folding space becomes folding an object and simultaneously denies the spatial differentiation of disparate places in the universe while reifying the discrete object-like quality of interstellar space as a thing.

Herbert describes folding space as the ability to travel to any part of the universe without moving, and the "Spacing Guild," whose navigators fold space, hold a monopoly on this interstellar travel (1965:22). Their augmented abilities, from spice consumption, allow a monopoly over interstellar space as object - something we might also consider as a monopoly on a particular kind of OOO thinking.

Writing on the "poetics of spice" and the "Romantic self-reflexive consumer," Morton notes that in Dune "spice rules all, from extraterrestrial trade to internal states of mind" $(2001: 1,7)$. In his broader project on the poetics of spice, Morton (2000) looks at spice as both material and metaphor in terms of exotic desire and consumption. In this earlier work, Morton's analysis of 
spice suggests productive relationships between materialism and formalism - things as objects and as metaphors or abstractions. In Dune, spice works to reveal not truth or more knowledge of the universe, but the underlying withdrawal of things posited by OOO. Spice reveals the world as "an unpredictable flow of time-and-space relations" and using spice "enables a more nuanced sense of that unpredictability" (Morton 2001:13).

In his writing about Dune, Morton evokes Brian Eno whose ambient music-scapes he describes as "spatialized form[s] of textuality" which undermine the distinctions between figure and ground (Morton 2001:16). While writing these words about interstellar space, I have been listening to my usual writing-about-space music, which includes Brian Eno's 1983 album “Apollo." Eno's album was inspired by NASA's Apollo 11 Moon mission and when asked about his memories of that moon landing, he responded:

I remember it very, very well. I watched it in the house of my painting tutor at art school, and I remember the very eerie sensation of watching on his little black and white television and then looking up at the moon and being absolutely shocked at the idea of what was happening there at that moment in time. It was one of those strange moments when time closes up on you and something that seems fictional and fantastic suddenly becomes real. [Highfield 2009:n.p.]

Eno's music spatializes the past/future rift that $\mathrm{OOO}$ locates in the absence of the present, and this rift also reflects Eno's experience of the Moon landing. Eno describes time closing up on him, echoing Morton's language about the "temporal undulation" of hyperobjects (2013:24). Eno's ambient compositions, whether for Moon landings (1983) or airports (1978) are then compositions that serve as soundtracks for hyperobjects.

When David Lynch directed a filmic interpretation of Dune (1984), he borrowed elements from throughout the series but focused primarily on the first book. Lynch's film has a relationship to the books much like Morton's evocation of "a radar signal reflected from the tip of an iceberg" (Morton 2012:230). This image of the radar signal appears when Morton discusses Derrida's 
assertion that there is nothing outside the text/there is no outside-text ([I]l n'ya pas de hors-texte). For Morton (via Heidegger), the "flicker on the radar screen" is a trace (with all of the Derridean connotations in that phrase) of the non-human, and the human being is "merely the radio operator who receives the echo, who attunes herself to it" (Morton 2012:230).

Spivak writes that for Derrida the trace is "the part played by the radically other within the structure of difference that is the sign" (Derrida 1997:xvii). Another word for this trace is the track - the track marks, the evidence, that which is left behind. There is a trace of Herbert's writing in Lynch's filmic Dune, what Derrida might call a citation or signature. There is also a trace of Eno in Lynch's film soundtrack. One track on the album (out of 17) was written by Eno; track number nine is titled "Prophecy Theme" (Toto and Eno 1984). In Morton's poetics of spice, ingesting Melange gives the user a more nuanced sense of the "metastable world," with its "unpredictable flow of time-and-space relations" and to the mundane world this new sense "appears to be the gift of prophetic power" (Morton 2001:13). Listening to Eno's track written for Lynch's trace of Herbert's Dune, I often wonder if this is what prophecy sounds like - a question which becomes slightly less absurd through the lens of an OOO which allows for prophecy to become an object, in a universe of other objects.

Morton describes this permission to be an object as the "flatness" of OOO, because as he says: "hallucinations and the idea of purple are also objects, though perhaps not of the same kind as toilets and ozone" (Morton 2011:165). This flatness is liberating, as it allows me to think about the sounds made by the object "prophecy," while it is also disorienting as it removes the subject. As Morton writes: "we've become so used to hearing "object" in relation to "subject" that it takes some time to acclimatize to a view in which there are only objects, one of which is ourselves" (2011:165). 
Thinking about non-world worlds and non-space-interstellar-space in Herbert's Dune is about following these traces and tracks of objects. Writing, as Spivak says, "is the name of the structure always already inhabited by the trace" (Derrida 1997:xxxiv). But what is traced when I follow these tracks, and also what trace is tracked? To fold space, in Dune, is to prophetically see interstellar space as an object, it is something both of the mind and a real object, not an imagined or constructed one. In doing an anthropology of the interstellar, then, I am interested in how we might un-fold space. To unfold space is to take "interstellar space as an object" itself as an object of study, to tune in to the echoes of the hyperobjects across sites and scales and to pay attention to the worlds (real or imagined) we build around these radar reflections.

\section{Conclusion: Arriving in the Interstellar}

What then is essence? Essence is the arrivant, the never-present to-come of a thing. An infinitely exploded view of an object, under all possible lighting conditions and for all sentient beings, is not that object. [Morton 2012:235]

Through the lens of object-oriented ontology, interstellar space is not only an imaginary world and a world of imagination and not only a text we write, re-write, and cite. Interstellar space, seen as hyperobject, is an object of vast temporal and spatial dimension, aspects of which protrude into our everyday lived experiences. An anthropology of the interstellar takes this object-ness, and the protrusions, echoes, and signals of the hyperobject, as objects of study themselves. Interstellar space, as an object however, never arrives. It is not a space among planets or a place to visit, but rather the no-thing thing between stars - the space between stars. Interstellar space is an arrivant of space, the "never-present to-come" (Morton 2012:235), which is also, then, the essence of outer space. 
Ethnography of the interstellar-as-object is a description of the lives of objects among other objects in space. We, and everything we know, stand together on this planet. This planet is soaring through interstellar space at this very moment. There is a lurching sense of motion within this being-on-a-planet, it is the surging movement of "temporal undulation" found in all hyperobjects (2013:24). The Earth is circling the sun and the sun is on its own orbit, moving through the galaxy; and the galaxy? It too is heaving an inconceivable self across the universe. All the while, we imagine worlds elsewhere and otherwise - but we are already in them.

An anthropology of the interstellar unfolds space to show that we are already implicated in interstellar space - even more than NASA, 100YSS, SETI, and science fiction hope we will be in the future. The traces of interstellar space are all around us, standing beside us and inside us here on Earth. Looking at the interstellar through the lens of OOO shows that we are already travelling across space, already reaching interstellar space, already living on a world ship, already folding and unfolding space, and we always have been. Through OOO, interstellar space then becomes an object we can and do encounter at a many different scales. What was remote, insensate, and desolate out there in a world somewhere else becomes intimate, poetic, and inhabited here alongside other objects like me. 


\section{References Cited}

\section{YSS}

N.d. 100 Year Starship. http://100yss.org/, accessed April 5, 2015. Archived here: web.archive.org/web/20150405224445/http://100yss.org 2014 Video: Let's Make Human Interstellar Travel Capabilities a Reality Within the Next 100 Years. http://100yss.org, accessed September 20, 2014. Also appears at https://vimeo.com/58664628 under the title "100YSS Manifesto."

Azua-Bustos, Armando, James Benford, Alan P. Boss, David Brin, Lewis R. Dartnell, Paul C.W. Davies, Michael M. Davis, et al.

2015 Regarding Messaging to Extraterrestrial Intelligence (METI) / Active Searches for Extraterrestrial Intelligence (Active SETI). http://setiathome.berkeley.edu.

http://setiathome.berkeley.edu/meti_statement_0.html, accessed April 6, 2015.

Carrithers, Michael, Matei Candea, Karen Sykes, and Martin Holbraad 2010 Ontology Is Just Another Word for Culture Motion Tabled at the 2008 Meeting of the Group for Debates in Anthropological Theory, University of Manchester. Soumhya Venkatesan, ed. Critique of Anthropology 30(2): 152-200.

Cook, Jia-Rui C., D.C. Agle, and Dwayne Brown 2013 NASA Spacecraft Embarks on Historic Journey Into Interstellar Space. http://www.jpl.nasa.gov/news/news.php?feature=3897, accessed April 6, 2015.

Ceyssens, Frederik, Maarten Driesen, and Kristof Wouters 2012 On the Organisation of World Ships and Other Gigascale Interstellar Space Exploration Projects. Journal of the British Interplanetary Society 65: 134-139.

de Grasse Tyson, Neil

2015a The Future of Humanity with Elon Musk. SoundCloud. March 22.

https://soundcloud.com/startalk/the-future-of-humanity-with-elon-musk, accessed April 6, 2015.

2015b “Aliens Will Make Pets of Us.” In Case You Missed @ElonMusk on@StarTalkRadio Last Week. iTunes \& http://bit.ly/1IgXnPk. Microblog. @neiltyson. https://twitter.com/neiltyson/status/582657164155707393, accessed April 7, 2015.

Derrida, Jacques

1988 Limited Inc. Evanston, IL: Northwestern University Press.

1993 Aporias: Dying--Awaiting (one Another At) the "Limits of Truth" (mourir--S'attendre Aux "Limites De La Vérité"). Stanford, Calif.: Stanford University Press. 1997[1976] Of Grammatology. Gayatri Chakravorty Spivak, tran. Baltimore, Md.: Johns Hopkins University Press.

Eno, Brian

1978 Music for Airports. South Plainfield: Editions EG; Marketed by Jem Records. 
1983 Apollo: Atmospheres and Soundtracks. New York: EG ; Marketed and distributed by Caroline.

Ferguson, Reuben David

2002 A Brief History of Project Orion. M.A. Thesis, Florida Atlantic University.

Fife, Wayne

N.d. Imaginary World Studies: A Proposition for a New Subfield in Anthropology.

Unpublished MS, Department of Anthropology, Memorial University of Newfoundland.

Haraway, Donna Jeanne

1991a Simians, Cyborgs, and Women: The Reinvention of Nature. New York: Routledge.

1991b The Actors Are Cyborg, Nature Is Coyote and the Geography Is Elsewhere: Postscript

to "Cyborgs at Large." In Technoculture. Constance Penley and Andrew Ross, eds. Pp. 21-

26. Minneapolis: University of Minnesota Press.

Helmreich, Stefan

2014 Waves: An Anthropology of Scientific Things (The 2014 Lewis Henry Morgan

Lecture). HAU: Journal of Ethnographic Theory 4(3): 265-284.

Herbert, Frank

1965 Dune. Philadelphia: Chilton Books.

1969 Dune Messiah. New York: Putnam.

1976 Children of Dune. New York: Berkley Pub. Corp. : Distributed by Putnam.

1981 God Emperor of Dune. New York: Putnam.

1984 Heretics of Dune. New York: Putnam.

1985 Chapterhouse: Dune. New York: Putnam.

Highfield, Roger

2009 Apollo Special: Brian Eno's Moon Music. New Scientist, July 14: n.p.

Lynch, David, dir.

1984 Dune. Universal Home Video. Universal City, CA.

Matloff, Gregory L., and John Pazmino

1997 Detecting Interstellar Migrations. In Astronomical and Biochemical Origins and the

Search for Life in the Universe: Proceedings of the 5th International Conference on Bioastronomy, IAU Colloquium No. 161, Capri, July 1-5, 1996. Cosmovici, Cristiano Batalli International Conference on Bioastronomy, Stuart C Bowyer, Dan Werthimer, and IAU Colloquium, eds. Pp. 757-759. Bologna, Italy: Editrice Compositori.

Memory Alpha

N.d. V'ger. Memory Alpha. http://en.memory-alpha.org/wiki/V\%27ger, accessed April 6, 2015.

Melville, Herman 
1892 Moby Dick, or the White Whale. Boston: St. Botolph Society.

Morton, Timothy

2000 The Poetics of Spice: Romantic Consumerism and the Exotic. Cambridge, UK; New

York: Cambridge University Press.

2001 Imperial Measures: Dune, Ecology and Romantic Consumerism. Romanticism on the $\operatorname{Net}(21):$ :.p.

2011 Here Comes Everything: The Promise of Object-Oriented Ontology. Qui Parle: Critical

Humanities and Social Sciences 19(2): 163-190.

2012 Ecology without the Present. Oxford Literary Review 34(2): 229-238.

2013 Hyperobjects: Philosophy and Ecology after the End of the World. Minneapolis:

University of Minnesota Press.

Myers, Natasha

2008 Molecular Embodiments and the Body-Work of Modeling in Protein Crystallography. Social Studies of Science 38(2): 163-199.

NASA JPL

N.d. Voyager Enters Interstellar Space - NASA Jet Propulsion Laboratory. http://www.jpl.nasa.gov/interstellarvoyager/, accessed April 5, 2015. Archived here: http://web.archive.org/web/20150405224155/http://www.jpl.nasa.gov/interstellarvoyager

Penley, Constance, and Andrew Ross, eds.

1991 Technoculture. Minneapolis: University of Minnesota Press.

Porter, Jennifer E., and Darcee L. MacLaren 1999 Star Trek and Sacred Ground: Explorations of Star Trek, Religion, and American Culture. Albany: State University of New York Press.

Saint-Exupéry, Antoine de 1943 The Little Prince. Katherine Woods, tran. New York: Harcourt, Brace \& World.

Sagan, Carl 1994 Pale Blue Dot: A Vision of the Human Future in Space. New York: Random House.

Schmidt, G. R., J. A. Bonometti, and C. A. Irvine 2002 Project Orion and Future Prospects for Nuclear Pulse Propulsion. Journal of Propulsion and Power 18(3): 497-504.

Shostak, Seth

2015 Should We Keep a Low Profile in Space? The New York Times, March 27. http://www.nytimes.com/2015/03/28/opinion/sunday/messaging-the-stars.html, accessed April 5, 2015.

Toto, and Brian Eno 1984 Dune: Original Motion Picture Soundtrack. New York: Polydor. 
Williams, Stephen 2014 Ascension. CBC/Syfy.

Wise, Robert, dir.

1979 Star Trek: The Motion Picture. Paramount Pictures. Hollywood. 